\title{
A Study To Evaluate The Effectiveness Of Back Strengthening Exercise To Relieve Low Back Pain Among Nursing Students In Selected Hostel At Salem.
}

\author{
Ms. Asha .K. Thomas ${ }^{1}$, Prof.S.Maragatham ${ }^{2}$, Mrs.K.S.Pushpalatha ${ }^{3}$ \\ ${ }^{I}$ Student, Shanmuga College of Nursing, Salem - 636007,Tamil Nadu, India \\ ${ }^{2}$ Principal, Shanmuga College of Nursing, Salem - 636007,Tamil Nadu, India \\ ${ }^{3}$ Lecturer, Department of Medical \& Surgical Nursing, Shanmuga College of Nursing, Salem-636007,Tamil \\ Nadu, India
}

\begin{abstract}
:
Background: Over a lifetime 80\% of the people have low back pain. About nine out of ten adults experience low back pain in their life time. Low back pain occurs in females mostly among adult girls mainly due to some everyday activity or poor posture. In India, occurrence of low back pain is alarming; nearly 60\% of the people in India have significant back pain. This study aimed at relieving low back pain among nursing students by back strengthening exercise.

Method: The pre-experimental study was conducted by using one group pretest posttest research design in selected nursing hostel at Salem.

Results: The mean pretest level of low back pain among the samples before the practice of back strengthening exercise was 5.50 and the mean posttest level of low back pain among the samples after the practice of back strengthening exercise was 0.03. There was no association between the mean pretest level of low back pain among samples with their BMI but there was association between the mean pretest level of low back pain among samples with their age and class.

Conclusion: The back strengthening exercise proved to be effective in relieving low back pain.

Keywords: Effectiveness, Back strengthening exercise, Low back pain, Nursing students.

\section{Introduction}

Low back pain is an important concern. . Over a lifetime $80 \%$ of the people have low back pain. About nine out of ten adults experience low back pain in their life time. Back pain can be prevented if exercise (core-strengthening exercises), maintaining proper body posture while sitting, standing and proper body mechanics while lifting things are practiced. As a health professional the nurse has a major responsibility in providing adequate information regarding proper postural maintenance and practicing exercises which strengthen the back muscles.
\end{abstract}

\section{Statement}

A study to evaluate the effectiveness of back strengthening exercise to relieve low back pain among nursing students in selected nursing hostel at Salem.

\section{Objectives}

1. To observe the existing postural maintenance among nursing students in hostel.

2. To prepare and validate the back strengthening exercise to reduce low back pain among samples.

3. To assess and compare the level of intensity of low back pain before and after the back strengthening exercise among the samples.

4. To find the association between the pretest level of intensity of low back pain among the samples with their demographic variables (BMI, Age, Class).

\section{Hypotheses (Level of significance at $p<0.05$ )}

$\mathrm{H}_{1}$ : The mean post-test level of back pain will be less than the mean pre-test level of back pain among samples.

$\mathrm{H}_{2}$ : There will be significant association between the mean pre-test level of low back pain among samples with their demographic variables ( BMI ,Age, Class)

\section{Method}

1. Effectiveness: It refers to the difference between the mean pre test \& post test level of pain with the help of back strengthening exercise. 
a. Level of back pain: It refers to the level of discomfort one experiences in the lumbar region. In this study, it refers to the pain experienced by the nursing students in the lumbar and sacral region and is measured by using the Visual Analogue Scale.

b. Postural maintenance: It refers to the proper maintenance of position to relieve low back pain and is assessed by their postures. In this study it refers to the posture maintained by the nursing students during sitting and standing.

Postural maintenance were assessed during sitting and standing by non participatory approach. A. In sitting the following areas were assessed: Sitting with back support and Sitting without back support. B. In standing the following areas were assessed: Standing with foot well supported and Standing with foot not well supported.

c. Back strengthening exercise: It refers to those exercises performed by the nursing students which help to strengthen the lower back muscles. Mainly three exercises were taught. They were erector spinae stretching exercise, extension exercise and exercise while standing.

2. Exercise performance: It refers to the back strengthening exercise done by the samples under the supervision of the researcher for 30 days by participatory revealed observatory method where the score was given as completely done-2, partially done- 1 and not done- 0 . The pre-experimental study was conducted by using one group pre-test post-test design in selected nursing hostel at Salem.

The Gate Control Theory of Pain was chosen for conceptual framework for this study.

The total sample size of the study was 30 which used the non probability purposive sampling technique. The researcher observed the existing postural maintenance among 30 nursing students in the areas of sitting with back support, sitting without back support, standing with foot well supported and standing with foot not well supported. Then 30 students with low back pain were selected as samples and their postural maintenance were observed by non participatory concealed approach in the areas of sitting with back support, sitting without back support, standing with foot well supported and standing with foot not well supported. The researcher introduced herself to the samples and obtained written consent from the samples. The pre-test was done by using the self report checklist to assess the intensity of low back pain. On the same day the back strengthening exercise were taught to the samples till the $5^{\text {th }}$ day. Under the supervision of the researcher the exercise were practiced by the samples for the next 25 days. On the $30^{\text {th }}$ day post-test was conducted and the importance of maintaining correct posture was taught to the samples.

\section{Findings}

Total percentage distribution of samples by their pre-test and post-test level of low back pain among samples.

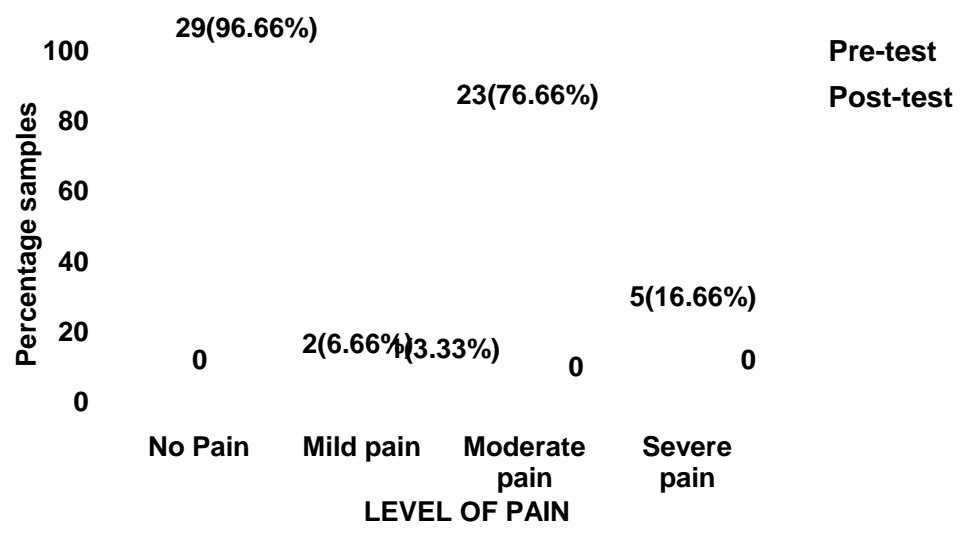

Fig-1: Bar diagram shows the pre-test and post-test percentage level of low back pain among samples.

Table 1: Mean pre-test, Mean post-test, standard deviation and paired ' $t$ ' value of low back pain among samples.

$\mathbf{n}=\mathbf{3 0}$

\begin{tabular}{|l|l|l|l|l|l|l|}
\hline \multirow{2}{*}{ Group } & \multicolumn{2}{|l|}{ Pre test } & \multicolumn{2}{l|}{ Post test } & \multirow{2}{*}{ df } & Paired 't' value \\
\cline { 2 - 7 } & Mean & SD & Mean & SD & \\
\hline $\begin{array}{l}\text { Nursing students with } \\
\text { low back pain }\end{array}$ & 5.50 & 1.256 & 0.03 & 0.1705 & 29 & 22.45 \\
\hline
\end{tabular}

Level of significance $=0.05 ; \mathrm{t}_{29}=2.045$ 
Analysis shows that,

- In pre-test, $6.66 \%$ had mild pain, $76.66 \%$ had moderate pain and $16.66 \%$ had severe pain.

- In post-test, $3.33 \%$ had mild pain and $96.66 \%$ had no pain.

- The mean pre-test score for level of low back pain was 5.50 and was reduced to 0.03 in post-test. In posttest with $\mathrm{t}_{29}$ was 22.45 , which is more than the table value of $\mathrm{p}<0.05$ level of significance.

- There was no significant association between BMI with the mean pre-test level of low back pain and the chi-square value is 3.273 .

- There was significant association between age with the mean pre-test level of low back pain and the chisquare value is 14.61 .

- There was significant association between class with the mean pre-test level of low back pain and the chisquare value is 11.94 .

\section{Conclusion}

The mean pre test level of low back pain among samples were high (5.50). After intervention (back strengthening exercise) the level of low back pain among samples were low(0.03). This revealed that back strengthening exercise was very effective in reducing low back pain among nursing students.

\section{Limitations:}

- The study was limited to female nursing students with low back pain.

- The study was limited to nursing hostel.

- The study was limited to 30 samples.

\section{Recommendations}

- A similar study can be conducted in different occupational risk for low back pain.

- A comparative study can be conducted on large samples in different settings.

- A similar study can be conducted in acute setting.

- A similar study can be conducted in staff nurses in different hospital.

\section{Reference}

[1]. Hickey.J., (1997), "The clinical practice of neurological and neuro surgical nursing", 4 th edition, Lippincott, Philadelphia

[2]. Moffett Klaber, et.al., (1999), "A longitudinal study of low back pain in student nurses", abstract retrieved from www.pubmed.gov.in (PMID:8335430) on 15.4.10

[3]. Bell. JA., Burnet. A., (2009), "Exercise for the primary, secondary and tertiary prevention of low back pain in the work place: A systematic review", Occupational rehabilitation, March, Vol-19(1): Page No. 8 - 24, PMID-00006162, (Pubmed-indexed for medline).

[4]. Mitchell, et.al., "Identification of modifiable personal factors that predict new onset low back pain: A prospective study of female nursing student", The Clinical Journal of pain, Vol-26(4): Page No. 275-283.

[5]. Videman, T., et.al., (2005), "Low back pain among nurses : A follow up beginning at entry to the nursing school", Spine (Phila PA, 1976), Vol15, 30(20), Page No.2334-41, PMID -16227898 (Pubmed indexed for Medline)

[6]. Loney. PL., et.al., (1999), "The prevalence of low back pain in adults : a methodological review of the literature", Physical Therapy, Vol-79(4), Page No.374-396, PMID - 10201544, (Pubmed indexed for Medline). 